\title{
High-density lipoproteins during sepsis: from bench to bedside
}

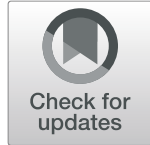

\author{
Sébastien Tanaka ${ }^{1,2}$, David Couret ${ }^{1,3}$, Alexy Tran-Dinh ${ }^{2,4}$, Jacques Duranteau ${ }^{5,6}$, Philippe Montravers ${ }^{2,7}$, \\ Anna Schwendeman ${ }^{8,9}$ and Olivier Meilhac ${ }^{1,3^{*}}$
}

\begin{abstract}
High-density lipoproteins (HDLs) represent a family of particle characterized by the presence of apolipoprotein A-I $(a p o A-I)$ and by their ability to transport cholesterol from peripheral tissues back to the liver conferring them a cardioprotective function. HDLs also display pleiotropic properties including antioxidant, anti-apoptotic, antithrombotic, anti-inflammatory, or anti-infectious functions. Clinical data demonstrate that HDL cholesterol levels decrease rapidly during sepsis and that these low levels are correlated with morbi-mortality. Experimental studies emphasized notable structural and functional modifications of HDL particles in inflammatory states, including sepsis. Finally, HDL infusion in animal models of sepsis improved survival and provided a global endothelial protective effect. These clinical and experimental studies reinforce the potential of HDL therapy in human sepsis. In this review, we will detail the different effects of HDLs that may be relevant under inflammatory conditions and the lipoprotein changes during sepsis and we will discuss the potentiality of HDL therapy in sepsis.
\end{abstract}

Keywords: Endothelium, High-density lipoprotein (HDL), Inflammation, Intensive care unit (ICU), Lipopolysaccharide (LPS), Sepsis, Sepsis therapy

\section{Background}

Despite a better comprehension of this entity, sepsis remains a pathology with a high rate of morbi- and mortality worldwide [1]. Pathophysiological pathways involved in sepsis are complex, including pro- and antiinflammatory signaling along with major nonimmunological responses such as cardiovascular, neuronal, autonomic, hormonal, and metabolic responses, as well as activation of coagulation [2]. Recent definitions and consensus underline that sepsis is clearly defined as a life-threatening organ dysfunction caused by deregulated host response to infection [1]. The failure of therapies using specific anti-inflammatory treatments may be due to the complexity of sepsis signaling, modulation

\footnotetext{
* Correspondence: olivier.meilhac@inserm.fr

'Université de La Réunion, INSERM, UMR 1188 Diabète athérothombose

Réunion Océan Indien (DéTROI), Saint-Denis de La Réunion, France

${ }^{3} \mathrm{CHU}$ de La Réunion, Saint-Pierre de la Réunion, France

Full list of author information is available at the end of the article
}

and pattern, and finally to the poor understanding of the pathophysiology.

High-density lipoproteins (HDLs) represent a family of particles characterized by their ability to transport cholesterol from peripheral tissues back to the liver that confers to them an anti-atherogenic protective effect. Many experimental studies emphasize on other pleiotropic properties of HDLs, including anti-inflammatory, antiapoptotic, or antioxidant functions [3, 4]. Furthermore, HDLs have the property to bind and neutralize lipopolysaccharide (LPS) [5] that could be particularly relevant in septic conditions. Other studies have also demonstrated that infusion of reconstituted HDL (rHDL) or HDL mimetic particles decreased morbi- and mortality in animal models of sepsis [6].

Because of their pleiotropic protective effects, HDLs may represent a potential future therapeutic target to be explored in human sepsis. The objectives of this present review are to describe HDL properties that can play a

(c) The Author(s). 2020 Open Access This article is licensed under a Creative Commons Attribution 4.0 International License which permits use, sharing, adaptation, distribution and reproduction in any medium or format, as long as you give appropriate credit to the original author(s) and the source, provide a link to the Creative Commons licence, and indicate if changes were made. The images or other third party material in this article are included in the article's Creative Commons licence, unless indicated otherwise in a credit line to the material. If material is not included in the article's Creative Commons licence and your intended use is not permitted by statutory regulation or exceeds the permitted use, you will need to obtain permission directly from the copyright holder. To view a copy of this licence, visit http://creativecommons.org/licenses/by/4.0/ The Creative Commons Public Domain Dedication waiver (http://creativecommons.org/publicdomain/zero/1.0/) applies to the data made available in this article, unless otherwise stated in a credit line to the data. 
role in sepsis and to summarize clinical and experimental studies involving HDL during sepsis.

\section{HDL structure and diversity}

Lipoproteins are macromolecular particles composed by proteins including apolipoproteins associated with a phospholipid layer containing a lipid core consisting in free cholesterol, cholesterol esters, and triglycerides [7]. They are classified according to their density, which is proportional to their protein content: chylomicrons, very low-density lipoproteins (VLDLs), intermediate-density lipoproteins (IDLs), low-density lipoproteins (LDLs), and high-density lipoprotein (HDLs), being the particles with the highest protein content.

Specifically, HDLs are defined by a density ranging from 1.063 to 1.21 . To characterize this lipoprotein population, different techniques are used and underline the heterogeneity of HDL subclasses. Ultracentrifugation allows isolation of HDL fractions into HDL2a, HDL2b, and HDL3, whereas electrophoresis on gradient gels separates HDL particles by size (HDL2a, HDL2b, HDL3a, HDL3b, HDL3c). Two-dimensional gel electrophoresis has been used to separate HDL populations according both to their charge and size into small pre- $\beta$ and large $\alpha 1-\alpha 4$ HDL particles. Rosenson et al. have suggested a new classification defining $5 \mathrm{HDL}$ subclasses on the basis of physical and chemical properties and named very large, large, medium, small, and very small HDL particles [8]. Finally, HDL particles may be classified according to their major lipoprotein contents [7].

As compared to other lipoproteins, HDLs are also characterized by their abundant protein content and protein diversity. Although HDL particles are mainly composed by ApoA-I, proteomic analysis has emphasized the numerous proteins that are transported by HDLs, including enzymes, acute phase response proteins, complement system proteins, and proteinase inhibitors [9].

\section{HDL metabolism and main function: reverse transport of cholesterol (Fig. 1)}

One major function of HDL metabolism is the reverse cholesterol transport (RCT) permitting the efflux of cholesterol from peripheral cells back to the liver that confers to HDL a cardiovascular protective effect $[10,11]$.

The first step of the biosynthesis of HDL particles is the release of lipid-free or lipid-poor apolipoprotein A-I by the liver and intestine. Lipid-poor apoA-I will then acquire phospholipids and free cholesterol via their interaction with ATP-binding cassette transporter A1 (ABCA1), which is a membrane transporter protein mainly expressed by macrophages and hepatocytes, but also in the brain and other tissues. With the acquisition of these lipids, HDL particles become discoidal, forming disk-shaped pre- $\beta$ [12]. Then, lecithin-cholesterol acyltransferase (LCAT), which is activated by apoA-1, will esterify free cholesterol. Cholesterol esterification leads

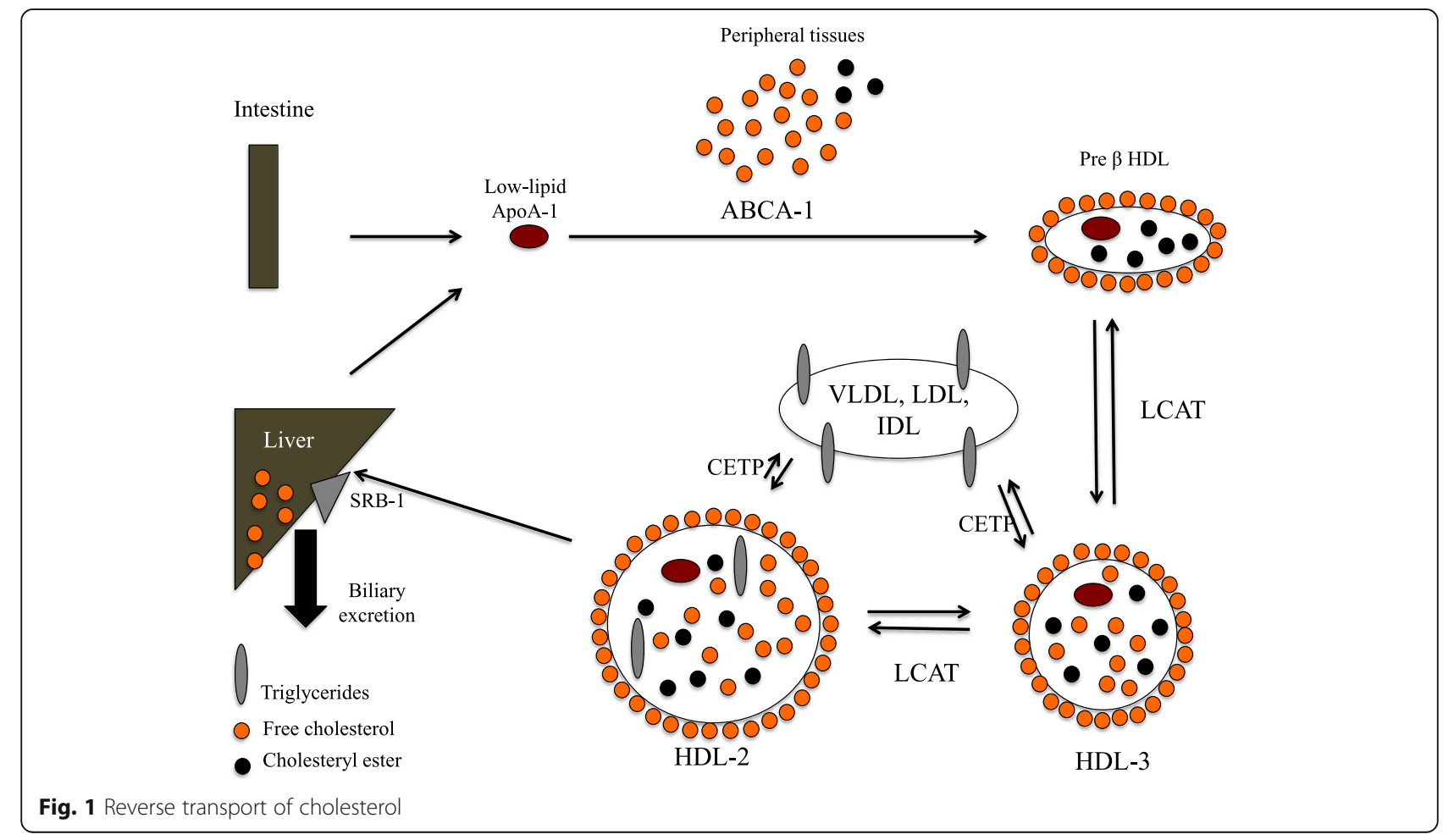


to a structural modification of HDL particles, which become smaller, dense, and spherical $\left(\mathrm{HDL}_{3}\right)$. $\mathrm{HDL}_{3}$ particles continue to accept free cholesterol and apolipoproteins forming bigger and lipid-rich particles named $\mathrm{HDL}_{2}$. $\mathrm{HDL}_{2}$ and $\mathrm{HDL}_{3}$ have the possibility to exchange esterified cholesterol against triglycerides (TG) from other lipoproteins (VLDL, IDL, LDL). TG molecule is bigger than esterified cholesterol, which participates in increasing the size of HDL particles. This important remodeling system is performed by cholesteryl ester transfer protein (CETP).

$\mathrm{HDL}_{2}$ is then removed from the circulation by the liver via the scavenger receptor class B type I (SRB1), leading to the degradation of cholesterol esters by hepatocytes and their excretion into the bile. This interaction with SRB1 releases lipid-poor Apo A-I, which initiates a new cycle of RCT. The second mechanism of the degradation of cholesterol esters is through CETP which can transfer cholesterol esters from HDL particles to TG-rich lipoproteins (VLDL and LDL) and then cholesterol finally reaches the liver when LDL particles are taken up by the liver via the LDL receptor.

\section{HDL cholesterol (HDL-C) levels vs HDL RCT functionality}

The current paradigm that HDLs are protective for cardiovascular diseases relies mainly on the results of the Framingham Study that reported a 2-3\% decrease in coronary artery disease risk with each increase by $1 \mathrm{mg} /$ $\mathrm{dL}$ in HDL-C [13]. Most of the epidemiological studies have evaluated the cholesterol concentration in the nonprecipitable lipoprotein fraction of plasma/serum, assumed to be "HDL-C"; however, this concentration only poorly reflects the capacity of HDL particles to reverse transport the cholesterol from peripheral tissues back to the liver. Cholesterol efflux capacity can be evaluated in vitro, using macrophages, and has been shown to be inversely correlated to carotid intima-media thickness and CAD risk, independently of the HDL-C levels [14]. This functional RCT assay is also inversely related to the incidence of cardiovascular events in a population-based cohort [15]. A wealth of genetic and interventional studies suggests that increasing HDL-C levels is not sufficient to limit CVD risk. On the one hand, Mendelian randomization studies report that single nucleotide polymorphism modulating HDL-C levels such as variants of endothelial lipase [16] or phospholipid transfer protein [17] did not impact on CVD risk prediction (see metaanalysis in [18]). On the other hand, clinical trials using cetrapibs (CETP inhibitors) showed that, albeit raising HDL-C levels, these molecules were unable to improve cardiovascular outcomes [19], suggesting that evaluation of HDL functionality should be an important readout for testing new therapies.

\section{Pleiotropic effects of HDL (Fig. 2)}

Lipopolysaccharide (LPS) and lipoteichoic acid (LTA) binding and neutralization properties of HDL (Fig. 3)

LPS is the major component of the outer membrane of Gram-negative bacteria. In noncapsulated strains, LPS is exposed on the cell surface. Numerous studies have demonstrated that all lipoproteins (chylomicrons, VLDL, LDL, and HDL) are capable to bind Gram-negative LPS. However, it is clearly established that LPS preferentially binds HDL particles relative to other lipoproteins [20]. Levels et al. have incubated different labeled LPS chemotypes with delipidated or normal plasma and determined LPS fluorescence profiles by high-performance gel permeation chromatography [21]. These authors demonstrated that LPS binding to lipoproteins is highly specific and that HDLs have the highest binding capacity for LPS as compared to that of other lipoproteins. Furthermore, Levine et al. have shown that transgenic mice expressing human Apo A-I displayed lower cytokine levels after LPS injection compared to control mice [22]. This interaction is facilitated by the action of specific lipid transfer proteins such as CETP, PLTP, and LPS-binding protein (LBP) [23]. These specific proteins permit the transfer of LPS to lipoproteins. For example, as described by Vesy et al., mainly LBP but also PLTP can extract LPS from bacterial membranes and transfer it to HDL particles in human serum [24].

However, the mechanisms underlying the association between LPS and HDLs remain unclear: LPS lipid A diglucosamine-phosphate region seems to be the key part of LPS molecules allowing the interaction between LPS and HDL particles [25]. Furthermore, HDL particles are probably not sufficient to neutralize the biologic activity of LPS [5]. Theoretically, LBP is required to form a complex between LPS and CD14 able to bind HDL particles, permitting its neutralization.

Gram-positive do not have LPS, but lipoteichoic acid (LTA), an amphiphilic molecule formed by a hydrophilic polyphosphate polymer linked to a neutral glycolipid which is a major immunostimulatory component for these bacteria. The association of LTA with lipoproteins shows a striking similarity with that of LPS. HDL seems to have the highest affinity for LTA [26]. Grunfeld et al. have demonstrated that HDL can inhibit macrophage activation by LTA [27].

\section{Inhibition of adhesion molecule expression}

During sepsis and inflammatory states, the adhesion of leukocytes to the endothelium is a key step allowing their migration within the tissues [2]. Cockerill et al. have shown that physiological concentrations of human isolated HDLs inhibited in vitro the expression of leukocyte adhesion molecule expression (V-CAM-1, ICAM-1, E-selectin) on endothelial cells induced by pro- 


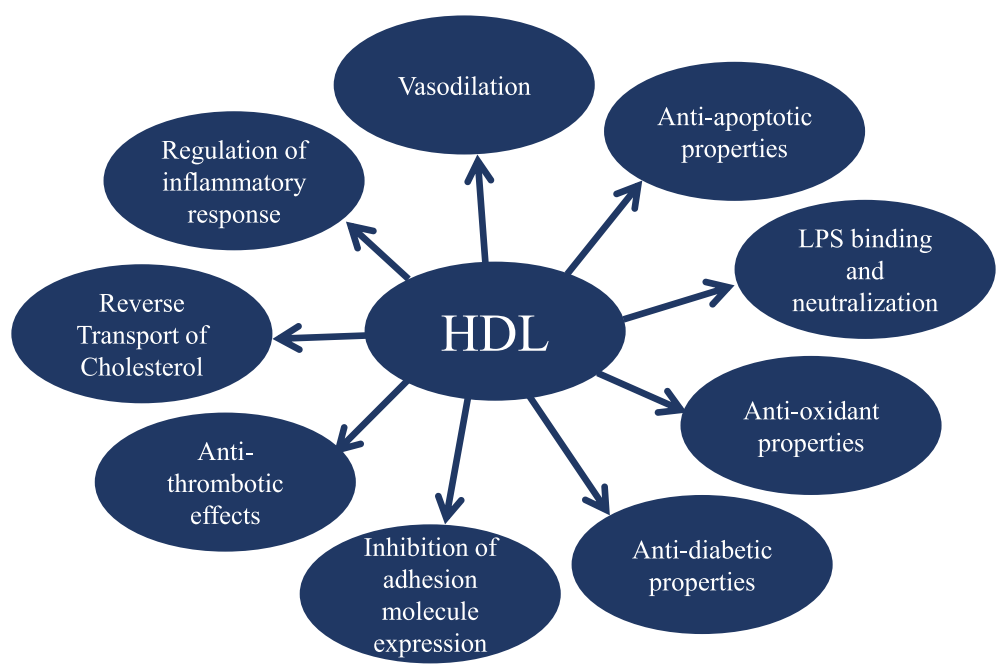

Fig. 2 Pleiotropic properties of HDL

inflammatory cytokines [28]. Reconstituted HDLs also inhibited the TNF $\alpha$-induced expression of V-CAM-1. The same authors have confirmed this action in vivo in a porcine model of inflammation [29]. Another study emphasized the fact that rHDLs attenuated adhesion molecule expression in a rodent model of endotoxin shock whereas pretreatment of LPS-injected rats with rHDL limited the expression of P-selectin and ICAM-1 caused by endotoxin in the kidney [30]. Another possible mechanism of HDL protective effects is the modulation of transcription factors, which may decrease adhesion molecule expression via the inhibition of nuclear factor NF-kB activity [31].
Regulation of inflammatory response in macrophages

HDLs may also be a key modulator of inflammatory response in macrophages [32, 33]. One important finding is that HDLs stimulate the transcriptional regulator ATF3, which downregulates inflammatory pathways that may in turn decrease the inflammatory response in case of sepsis [34]. Moreover, Zhu et al. have shown in murine macrophages that human serum amyloid A (SAA) dramatically upregulates the expression and secretion of a group of phospholipases (sPLA2-IIE and sPLA2-V), which are late pro-inflammatory mediators family [35]. In this in vitro study using purified HDL, HDL dosedependently attenuated SAA-induced secretion of both
1.
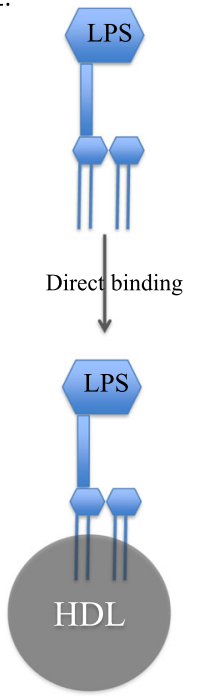

2.

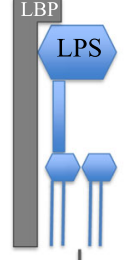

Binding via LBP

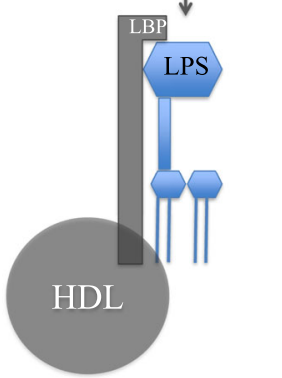

3.
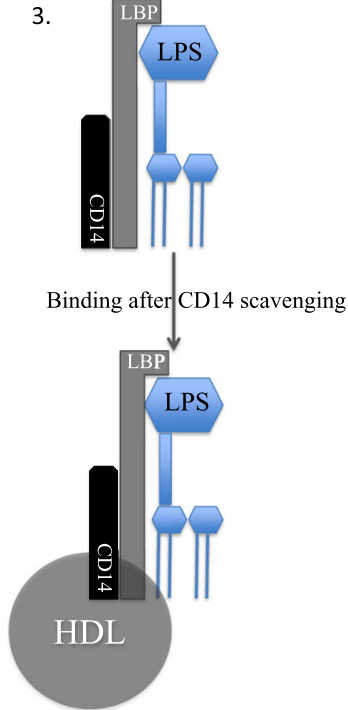

Fig. 3 Binding and neutralization of LPS by HDL: 3 potential pathways 
sPLA2-IIE and sPLA2-V. Lastly, Suzuki et al. demonstrated that HDLs inhibit a subset of LPS-stimulated macrophage genes that regulate the type I interferon response, independently of sterol metabolism, raising the possibility that regulation of macrophage transcriptome by HDLs might link innate immunity to cardioprotection [36].

\section{Microvascular vasodilation and endothelium repair}

HDLs have the property to stimulate the endothelial NO synthase (eNOS), which is involved in inhibiting the adhesion of monocytes to the endothelium and promotes microvascular vasodilation [3]. This upregulation of eNOS expression is dependent on SR-B1 receptor. Specific subclasses of HDL particles bind with different affinity to SR-B1. For example, lipid-poor and lipid-free apoA-I have a lower affinity for this receptor, leading a reduced vasodilation property [37]. HDL particles can also stimulate the production of prostacyclin, which is a powerful vasodilator. Kontush et al. have shown that $\mathrm{HDL}_{3}$ sub-fraction had a better capacity to improve NO production than $\mathrm{HDL}_{2}$ because of its enrichment of sphingosine-1-phosphate (S1P), which stimulates the production of prostacyclin [38]. Moreover, in a population of coronary artery disease patients, Sattler et al. described that reduced S1P content in HDL particles abrogated their vasodilatory capacity, contributing to HDL dysfunction [39]. S1P-loading in vitro and in vivo increased eNOS activation and improved the vasodilatory property of HDLs $[39,40]$.

\section{Anti-thrombotic effects}

HDLs stimulate the endothelial production of $\mathrm{NO}$ and prostacyclin which are inhibitors of platelet activation. Furthermore, HDLs prevent platelet hyperreactivity by limiting intraplatelet cholesterol overload and the interaction of apoA-I on platelet ABCA1 and SRB1 receptors. This leads to the inhibition of the pro-coagulation cascade and subsequent clot formation [41]. HDLs may also prevent the endothelial thrombotic activation, by promoting prostacyclin and Cox 2 production and by reducing the expression of tissue factor and of adhesion molecules [42]. A direct anti-thrombotic property of HDLs has been reported, via the reduction of thrombus formation in a study involving a mutant form of human ApoA-I [43]. Furthermore, HDLs can enhance particular anticoagulant activity (inactivation of active factor $\mathrm{V}$ ) exerted by activated protein $\mathrm{C}$ and protein $\mathrm{S}$ [44]. A direct antiplatelet effect was also described in vivo and in vitro by reducing platelet aggregation induced by collagen, ADP, or thrombin [45].

\section{Antioxidant properties}

Paraoxonase (PON1) is an HDL-associated esterase, protecting lipoproteins against oxidation. PON1 is able to hydrolyze lipid peroxides and especially oxidized cholesteryl esters and phospholipids [46]. Moreover, PON1 also hydrolyzes phosphatidylcholines into lysophosphatidylcholines, which improve the bactericidal activity of neutrophils potentially resulting in a protective effect in experimental sepsis [47]. Shih et al. have demonstrated that PON1-deficient mice are susceptible to oxidative stress and that HDLs isolated from these mice were unable to prevent LDL oxidation [48]. The global antioxidant effect of HDLs is evaluated via their capacity to inhibit LDL oxidation. This property consists in the transfer of oxidized lipids from oxidized LDL (oxLDL) (hydroperoxides and lysophosphatidylcholine) to HDL particles and by the inactivation of oxidized lipids. Lastly, HDLs are able to limit oxidation by decreasing ROS production via the inactivation of neutrophil $\mathrm{NADPH}$ oxidase [49]. Oxidation is an important phenomenon observed in sepsis [50], and reduced HDL antioxidant function may participate in sepsis progression/severity.

\section{Anti-apoptotic properties}

HDLs exert a protective effect on endothelial cell apoptosis by interfering with both receptor-mediated death signaling and mitochondrial apoptotic pathways. Suc et al. have demonstrated that HDLs have the capacity to inhibit apoptosis of endothelial cells induced by oxLDL [51]. In oxLDL-induced apoptosis, HDLs were shown to interact with the endoplasmic reticulum. As underlined by Nofer et al., Akt signaling, a major anti-apoptotic pathway, is stimulated by HDLs in a model of endothelial cell apoptosis (HUVECs) [52]. In this study, HDLs were also capable of inhibiting caspase- 3 and caspase- 9 activation. Theilmeier et al. have shown in vitro and an in vivo mouse model of myocardial ischemia/reperfusion that HDLs and its sphingolipid component S1P reduced cardiomyocyte apoptosis [53]. Moreover, a direct infusion of native HDLs or a S1P receptor agonist reduced cardiomyocyte apoptosis, myocardial injury, and the size of myocardial infarction [54, 55]. Taken together, these anti-apoptotic effects and more globally endothelium protective effects of HDLs may limit the progression and the severity of sepsis, in which endothelium aggression play a pivotal role [3].

\section{Anti-diabetic properties}

Diabetic patients usually have a dyslipoproteinemia characterized by increased triglycerides and low HDL-C levels, with TG-enriched HDL resulting from a CETPmediated interchange of TG from TG-rich lipoproteins to HDLs [56]. HDL particles have been reported to 
display anti-diabetic properties by improving $\beta$ cell insulin secretion through ABCA1 and ABCG1: Brunham et al. have shown that mice with specific inactivation of ABCA1 in $\beta$ cells had markedly impaired glucose tolerance and defective insulin secretion but normal insulin sensitivity [57]. This was also demonstrated in carriers of disruptive mutations in ABCA1 Tangier disease patients [58]. Numerous experimental studies have also shown that HDLs improve insulin sensitivity [59-61]; Han et al. have demonstrated that ApoA-I possesses protective effects against diabetes via activation of AMPactivated protein kinase and that ApoA-I deletion in mice led to increased fat mass and impaired glucose tolerance [60]. In humans, HDLs from diabetic patients are dysfunctional [62]. An acute infusion of reconstituted HDs in thirteen patients with type 2 diabetes mellitus reduced plasma glucose by increasing plasma insulin levels and activating AMP-activated protein kinase in skeletal muscle [63].

\section{Lipoprotein changes during human sepsis}

In critically ill patients and especially in septic patients, a reduction in lipid and lipoprotein levels is well documented [64]. Clinical observations have shown that circulating levels of HDLs decrease during the acute phase of inflammatory state and especially during a sepsis [6568]. van Leeuwen et al. have demonstrated that lipoprotein levels rapidly drop up to $50 \%$ of initial concentrations in patients with severe sepsis and that this rapid reduction was particularly marked in LDL and HDL cholesterol levels [65]. We have compared HDL profiles between septic and trauma patients [69]. Although inflammation is exacerbated in these two entities, HDL-C levels were lower in septic patients, whereas their concentration was not altered in case of trauma. Interestingly, in a study involving healthy subjects, low HDL levels were correlated with increased inflammatory response to endotoxin challenge compared with subjects with normal or high HDL levels [70].

During sepsis, several hypotheses may provide explanation for this dramatic reduction, including an acute over-consumption of HDL particles, a decrease in liver HDL synthesis, especially in case of hepatic failure, and/ or an increased clearance following an upregulation of SRB1 [71]. In the context of sepsis characterized by a severe inflammation-induced capillary leakage, HDL particles may easily be redistributed from the intravascular to the extravascular compartment [65]. Another hypothesis would be a decrease of ApoA-I due to its replacement by serum amyloid A (SAA) in HDL particles at the early phase of sepsis [72]. SAA is able to displace ApoA-I from the surface of HDL particles, generating free ApoA-I, which is cleared faster by the kidney, thus contributing to reducing HDL-C levels and functionality [73].

The majority of these observational studies emphasized the negative correlation between HDL concentration and mortality $[66,67]$. A low HDL concentration at day 1 was significantly associated with an increased mortality and adverse clinical outcomes with a cut-off ranging from 20 to $25 \mathrm{mg} / \mathrm{dL}$ [67]. In a prospective study including 151 consecutive septic patients, a low apoA-I concentration was independently related to 30-day mortality [66]. Interestingly, a recent study has shown that variations in genes involved in HDL metabolism could contribute to changes in HDL-C levels but also to clinical outcomes following a sepsis [74]. These authors have identified a rare missense variant in CETP (rs1800777-A) that was associated with significant reductions in HDL-C levels during sepsis. In this study, carriers of the A allele had an increased mortality, more organ failure, and greater need for organ support compared to non-carriers.

However, other studies failed to find any link between HDL levels and mortality. We did not find any correlation between mortality and HDL concentration but a poor outcome defined as death or SOFA score $>6$ at day 3 was associated with lower HDL levels in a population of 50 septic patients [69]. van Leeuwen et al. did not find any correlation between lipoprotein concentrations in survivors and non-survivors [65]. Whereas triglycerides were associated with mortality in septic patients, no correlation was found with other lipoproteins and especially with HDL concentration [75].

HDL levels were also associated with morbidity in several studies [75, 76]: for example, in a 2-year follow-up of patients with septic shock, low HDL levels were associated with increased risk of sepsis-associated acute kidney injury (AKI) and a decrease in estimated glomerular filtration rate (eGRF) [76].

Moreover, because sepsis still remains an important cause of mortality and morbidity, early biomarkers could be useful to establish a diagnosis of sepsis and also to indicate its severity. To date, there is no biomarker that fulfills these objectives in terms of sensibility and specificity. Some authors have suggested that HDL levels could represent an early marker of sepsis severity. Chien et al. underlined the power of HDL and Apo A-I levels at day 1 to predict the overall 30-day mortality rate [67]. At ICU admission, according to Barlage et al. study [66], low HDL-C (AUC of the ROC 0.6, $p=0.049$ ) and low apoA-1 (AUC of the ROC 0.604, $p=0.041$ ) levels were predictive of sepsis-related mortality. In a cohort of 200 patients enrolled at the emergency department with clinically suspected sepsis, comparing to different variables such as white blood cell count, lactate, or platelets, HDL concentration was the best predictor of both 
development of multiorgan dysfunction syndrome and 28-day mortality [68].

\section{HDL function in inflammatory state}

Acute inflammation alters both lipoprotein composition and metabolism resulting in reduced anti-inflammatory properties, in particular for HDL particles [72]. Numerous remodeling in HDL composition are currently described during these inflammatory states, such as apoA-I dissociation from the particles, reduction of esterified cholesterol, and decrease in HDL-associated enzymes (LCAT, CETP, or PON1 for example) [65]. It is well established that the presence of blood endotoxins modulates HDL particle composition. For example, during infection and inflammation, SAA displaces apoA-I within HDL particles, thus becoming the predominant apolipoprotein of septic HDLs [72]. This observation was also described in inflammatory states following cardiac surgery with cardiopulmonary bypass [77].

HDL-associated PON-1 is also altered in septic condition. Novak et al. have described a dramatic decrease in PON-1 activity in septic patients versus controls [78]. The oxidative environment induced by sepsis could result in an increased binding of free radicals to PON-1, leading to an overall decreased plasma activity of this enzyme. Platelet-activating factor-acetylhydrolase (PAF$\mathrm{AH})$ activity, which is able to inhibit the formation of non-esterified fatty acid hydroperoxides from oxLDL, was also reported to be altered in septic condition [79]. With the reduction in plasma PAF-AH and PON1 activities during sepsis, HDLs display blunted protective effects against LDL oxidation [80].

Proteomic studies underlined the diversity of HDLassociated proteins in normal conditions [9]. HDL proteome is clearly modified during inflammatory conditions [81] and in particular in sepsis state [82]. Sharma et al. evaluated the host proteome response in septic patients secondary to community-acquired pneumonia (CAP) [82]. This analysis has shown alteration in the cytoskeleton, cellular assembly, movement, lipid metabolism, and immune response in septic patients. Focusing on apolipoproteins, the authors demonstrated a decrease of some apolipoproteins (ApoA-I, ApoA-II, ApoA-IV, ApoB, ApoC-I, ApoC-II, ApoC-III, and ApoE). A recent study on the lipidome showed a decrease in phospholipid concentration in hospital-acquired pneumonia [83].

Reverse cholesterol transport is also impaired in inflammatory conditions. Specifically, de la Llera et al. have shown that in twenty healthy adults, an endotoxemia induced by LPS ( $3 \mathrm{ng} / \mathrm{kg}$ ) administrated as an intravenous bolus infusion led to a reduced capacity of HDLs to efflux cholesterol in vitro [72]. Interestingly, when comparing the 10 oldest septic patients to the ten oldest healthy subjects, the cholesterol efflux was significantly reduced in septic patients $(24 \pm 1.2 \%)$ compared to control subjects $(31.5 \pm 1.0 \%)$ [84].

In this context, dysfunctional HDLs has emerged as a new concept in sepsis as it was well documented in other diseases such as atherosclerosis, stroke, or autoimmune pathology [77-79, 81, 85]. It is now clearly established that HDLs become dysfunctional during sepsis and are associated with a poor outcome.

HDL size is also affected during inflammation and infection [72]. de la Llera et al. have shown that LPS infusion in healthy volunteers led to a decrease of small- and medium-size particles without any change in the total number of HDL particles [72]. We have shown that HDL levels are dramatically decreased in the acute phase of septic shock and that there is a shift toward large HDL particles [86]. Another study underlined that both HDL size and HDL-C concentration were independently associated with coronary artery disease risk [87]. In a recent study involving 402 patients who underwent carotid MRI assessment for lipid-rich necrotic core plaques, HDL particle size was significantly associated with HDL efflux capacity suggesting that differences in HDL efflux capacity may be due to structural differences in HDL particles [88]. However, because different techniques are used to assess HDL size, correlation of size with function should be exploited with caution.

In the light of these observations, HDL-C concentration is probably not sufficient to characterize HDL function. Size modification and HDL remodeling leading to changes in composition appear to be more relevant to make HDL dysfunction more helpful in clinical practice. In this context, since both quantitative and qualitative modifications of HDL particles are observed in septic conditions, supplementation with functional HDL in experimental pre-clinical models should be tested.

\section{HDL-based therapies in experimental sepsis studies}

Because of HDL pleotropic properties, the drastic reduction of HDL concentration and the dysfunction observed during inflammatory states, reconstituted HDLs or apoA-I mimetic peptide infusion may represent a potential therapy in sepsis $[6,22,30,71,89-93]$. Moreover, ApoA-I knockout mice exhibited reduced LPS neutralization in serum relative to controls, supporting the concept of rising functional HDL levels as a therapeutic approach for sepsis [94].

Several apoA-I mimetic peptides such as peptide $4 \mathrm{~F}$ (Ac-DWFKAFYDKVAEKFKEAF-NH2) have been synthetized and are able to bind phospholipids and associate with native HDL particle [95]. Zhang et al. have shown in a rat model of sepsis that infusion of apoA-I decreased plasma IL- 6 concentration, improved the cardiac function, and reduced the mortality [96]. Other 
studies have demonstrated that this peptide attenuated kidney, heart, vascular, and lung injury and improved survival in experimental models of sepsis [90, 97].

Reconstituted HDLs (rHDLs) were also tested in septic models [30, 91]. Different types of rHDLs have been experimented, but rHDLs are usually prepared with a $1 /$ 150 ratio of apoA-1 to soybean phosphatidylcholine (PC) [98]. For example, McDonald et al. have shown that rHDL infusion limited renal injury and dysfunction and reduced the degree of histological tissue injury in the lung, liver, and intestine [30]. Recently, in 3 different experimental mouse models of sepsis, we demonstrated that infusion of rHDL improved survival, reduced inflammation in both plasma and organs, and decreased bacterial count [99]. Interestingly, immunohistological analysis of septic lungs emphasized that apoA-I reached and accumulated in pulmonary tissue in rHDL-injected mice, suggesting that HDL particles can locally exert their protective effects. Moreover, ${ }^{111}$ Indium bacterial labeling provided a potential hepatic bacterial clearance possibly promoted by HDL uptake.

An additional table underlines these different experimental sepsis studies in more detail (see Additional file 1).

\section{rHDLs or mimetic peptide infusion in human sepsis?}

In the cardiovascular field, rHDLs have been tested in atherosclerotic and diabetic patients. Thirteen patients with type 2 diabetes mellitus received rHDLs and saline in a randomized crossover design study [100]. Four and $72 \mathrm{~h}$ after rHDL infusion, the anti-inflammatory properties of isolated HDL increased. Interestingly, there was also an enhancement of cholesterol efflux.

In case of coronary atherosclerotic disease, Tardif et al. have investigated the effects of rHDLs $\left(\mathrm{CSL} 111^{\circ}\right)$ on the plaque burden as assessed by intravascular ultrasound (IVUS) [101]. In this randomized controlled trial, 183 patients were randomized to receive CSL $111^{\circ}(40 \mathrm{mg} / \mathrm{kg}$ or $80 \mathrm{mg} / \mathrm{kg}$ ) or placebo. Concerning the primary outcome of the study, there was no significant reduction in percentage change in atheroma volume or nominal change in plaque volume in $\mathrm{CSL} 111^{\circ}$ group compared with placebo.

In pre-clinical studies, the ability of HDLs to bind endotoxin has been well correlated with their phospholipid content [22]. These results motivated the development of a protein-free phospholipid emulsion containing phosphatidylcholine, soybean oil, and sodium cholate in order to bind and eliminate LPS. A double-blind placebo-controlled study has enrolled 20 volunteers receiving Escherichia coli endotoxin infusion of either an emulsion of $92.5 \%$ of phosphatidylcholine and $7.5 \%$ of triglyceride or placebo [102]. A lower neutrophil count and TNF $\alpha$ and IL-6 levels were measured in patients who received the emulsion.
This encouraging result involving volunteers led to perform a randomized placebo-controlled phase II multicenter trial evaluating a phospholipid emulsion infusion in Gram-negative severe sepsis. However, the Lipid Infusion and Patient Outcomes in Sepsis (LIPOS) study failed to reduce 28-day all-cause mortality or the onset of new organ failure [103]. Timing of administration, no standardized protocol of care in this international study recruiting in 31 countries, and the heterogeneity of the recruited patients may explain these disappointing results.

To date, no randomized study using rHDLs or mimetic peptides in septic patients has been carried out. However, Pajkrt et al. have tested the effects of rHDLs in human endotoxemia [104]: 8 healthy male volunteers were enrolled in a double-blind crossover randomized placebo-controlled study. rHDLs given as a 4-h infusion at the dose of $40 \mathrm{mg} / \mathrm{kg}$ dramatically reduced the endotoxin-induced inflammatory response: rHDL infusion reduced the endotoxin-induced clinical symptoms (less chills, myalgia, backache, or vomiting) and importantly reduced the release of TNF $\alpha$, IL-6, and IL-8 cytokines. Moreover, rHDL infusion was associated with a downregulation of CD14, the main LPS receptor on monocytes. The same team also reported that rHDL infusion can affect the fibrinolytic activity and can directly influence platelet function by reducing platelet aggregation leading a modification of the procoagulant state associated with endotoxemia [105].

\section{Conclusion}

To summarize, in addition to its well-documented role in reverse transport of cholesterol, HDLs display numerous pleiotropic effects such as LPS neutralization, endothelial protection, and antioxidant and anti-apoptotic properties. Inflammation states and especially sepsis decrease dramatically HDL levels and alter their composition, metabolism, and function. These findings strongly support the therapeutic potential of rHDL or HDL mimetic peptide infusion in sepsis. With an improvement of survival, experimental studies involving rHDLs or HDL mimetic peptides are encouraging. However, further experimental studies are needed to better characterize this new concept of HDL dysfunction that is markedly associated with a poor outcome. A better comprehension of the function of these particles should encourage the medical and scientific community to initiate clinical trials aiming at testing the effect of a HDL therapy in human sepsis.

\section{Supplementary information}

Supplementary information accompanies this paper at https://doi.org/10. 1186/s13054-020-02860-3.

Additional file 1. HDL-based therapies in experimental sepsis studies. The table presents different experimental studies testing reconstituted 
HDLs or mimetic peptide by notifying the type of animal and model used, the type of product and dose, the modes and the timing of administration.

\section{Abbreviations}

ABCA1: ATP-binding cassette A1; ABCG1: ATP-binding cassette sub-family $G$ member 1; AKI: Acute kidney injury; ApoA-l: Apolipoprotein A-l; CAP: Community-acquired pneumonia; CETP: Cholesteryl ester transfer protein; eGRF: Estimated glomerular filtration; eNOS: Endothelial NO synthase; HDL: High-density lipoprotein; HDL-C: HDL cholesterol; IDL: Intermediate-density lipoprotein; IVUS: Intravascular ultrasound; LBP: LPSbinding protein; LCAT: Lecithin-cholesterol acyltransferase; LDL: Low-density lipoprotein; LPS: Lipopolysaccharide; LTA: Lipoteichoic acid; oxLDL: Oxidized LDL; PAF-AH: Platelet-activating factor acetylhydrolase;

PC: Phosphatidylcholine; PLTP: Phospholipid transfer protein; PON1: Paraoxonase-1; RCT: Reverse cholesterol transport; SAA: Serum amyloid $A_{\text {; }}$ SOFA: Sepsis-related organ failure assessment; SRB1: Scavenger receptor class B type 1; VLDL: Very low-density lipoprotein

\section{Acknowledgements}

Not applicable.

\section{Authors' contributions}

ST and OM designed the review. All authors participated in drafting and reviewing. All authors read and approved the final version of the manuscript.

\section{Funding}

No funding applies.

\section{Availability of data and materials}

Not applicable.

\section{Ethics approval and consent to participate}

Not applicable.

\section{Consent for publication}

Not applicable.

\section{Competing interests}

The authors declare that they have no competing interests.

\section{Author details}

'Université de La Réunion, INSERM, UMR 1188 Diabète athérothombose Réunion Océan Indien (DéTROI), Saint-Denis de La Réunion, France. ${ }^{2} \mathrm{AP}-\mathrm{HP}$, Service d'Anesthésie-Réanimation, CHU Bichat-Claude Bernard, Paris, France. ${ }^{3} \mathrm{CHU}$ de La Réunion, Saint-Pierre de la Réunion, France. ${ }^{4}$ Inserm UMR1148, Laboratory for Vascular Translational Science Bichat Hospital, Paris, France. ${ }^{5}$ AP-HP, Service d'Anesthésie-Réanimation, Hôpitaux Universitaires Paris-Sud, Université Paris-Sud, Hôpital de Bicêtre, Le Kremlin-Bicêtre, France.

${ }^{6}$ Laboratoire d'étude de la Microcirculation, "Bio-CANVAS: biomarkers in CardioNeuroVascular DISEASES" UMRS 942, Paris, France. ${ }^{7}$ Inserm UMR1152. Physiopathologie et Epidémiologie des Maladies Respiratoires, Paris, France. ${ }^{8}$ Department of Pharmaceutical Sciences, College of Pharmacy, University of Michigan, Ann Arbor, Ml 48109, USA. ${ }^{9}$ Biointerfaces Institute, University of Michigan, Ann Arbor, Ml 48109, USA.

Received: 28 November 2019 Accepted: 30 March 2020 Published online: 07 April 2020

\section{References}

1. Singer M, Deutschman CS, Seymour CW, Shankar-Hari M, Annane D, Bauer $M$, et al. The Third International Consensus Definitions for Sepsis and Septic Shock (Sepsis-3). JAMA. 2016;315(8):801-10.

2. Angus DC, van der Poll T. Severe sepsis and septic shock. N Engl J Med. 2013;369(21):2063.

3. Tran-Dinh A, Diallo D, Delbosc S, Varela-Perez LM, Dang QB, Lapergue B, et al. HDL and endothelial protection. Br J Pharmacol. 2013;169(3):493-511.

4. Santos-Gallego CG, Badimon JJ, Rosenson RS. Beginning to understand high-density lipoproteins. Endocrinol Metab Clin N Am. 2014;43(4):913-47..
5. Wurfel MM, Kunitake ST, Lichenstein H, Kane JP, Wright SD. Lipopolysaccharide (LPS)-binding protein is carried on lipoproteins and acts as a cofactor in the neutralization of LPS. J Exp Med. 1994;180(3):1025-35..

6. Dai L, Datta G, Zhang Z, Gupta H, Patel R, Honavar J, Modi S, Wyss JM, Palgunachari M, Anantharamaiah GM, et al. The apolipoprotein A-I mimetic peptide $4 \mathrm{~F}$ prevents defects in vascular function in endotoxemic rats. J Lipid Res. 2010;51(9):2695-705.

7. Kontush A, Lindahl M, Lhomme M, Calabresi L, Chapman MJ, Davidson WS. Structure of HDL: particle subclasses and molecular components. Handb Exp Pharmacol. 2015;224:3-51.

8. Rosenson RS, Brewer HB, Chapman MJ, Fazio S, Hussain MM, Kontush A, et al. HDL measures, particle heterogeneity, proposed nomenclature, and relation to atherosclerotic cardiovascular events. Clin Chem. 2011;57(3):392-410.

9. Vaisar T, Pennathur S, Green PS, Gharib SA, Hoofnagle AN, Cheung MC, et al Shotgun proteomics implicates protease inhibition and complement activation in the antiinflammatory properties of HDL. J Clin Invest. 2007; 117(3):746-56.

10. Nofer JR, Kehrel B, Fobker M, Levkau B, Assmann G, von Eckardstein A. HDL and arteriosclerosis: beyond reverse cholesterol transport. Atherosclerosis. 2002;161(1):1-16.

11. Gordon T, Castelli WP, Hjortland MC, Kannel WB, Dawber TR. High density lipoprotein as a protective factor against coronary heart disease. The Framingham Study. Am J Med. 1977;62(5):707-14.

12. Rye KA, Clay MA, Barter PJ. Remodelling of high density lipoproteins by plasma factors. Atherosclerosis. 1999;145(2):227-38.

13. Gordon DJ, Probstfield JL, Garrison RJ, Neaton JD, Castelli WP, Knoke JD, et al. High-density lipoprotein cholesterol and cardiovascular disease. Four prospective American studies. Circulation. 1989;79(1):8-15.

14. Khera AV, Cuchel M, de la Llera-Moya M, Rodrigues A, Burke MF, Jafri K, et al. Cholesterol efflux capacity, high-density lipoprotein function, and atherosclerosis. N Engl J Med. 2011;364(2):127-35.

15. Rohatgi A, Khera A, Berry JD, Givens EG, Ayers CR, Wedin KE, et al. HDL cholesterol efflux capacity and incident cardiovascular events. N Engl J Med. 2014:371(25):2383-93.

16. Voight BF, Peloso GM, Orho-Melander M, Frikke-Schmidt R, Barbalic M, Jensen MK, et al. Plasma HDL cholesterol and risk of myocardial infarction: a mendelian randomisation study. Lancet Lond Engl. 2012;380(9841):572-80.

17. Vergeer M, Boekholdt SM, Sandhu MS, Ricketts SL, Wareham NJ, Brown MJ, et al. Genetic variation at the phospholipid transfer protein locus affects its activity and high-density lipoprotein size and is a novel marker of cardiovascular disease susceptibility. Circulation. 2010;122(5):470-7.

18. Holmes MV, Asselbergs FW, Palmer TM, Drenos F, Lanktree MB, Nelson CP et al. Mendelian randomization of blood lipids for coronary heart disease. Eur Heart J. 2015;36(9):539-50.

19. Doggrell SA. What have we learnt from the clinical outcomes trials with the cetrapibs? Curr Opin Lipidol. 2018;29(4):327-32.

20. Ulevitch RJ, Johnston AR, Weinstein DB. New function for high density lipoproteins. Their participation in intravascular reactions of bacterial lipopolysaccharides. J Clin Invest. 1979;64(5):1516-24.

21. Levels JHM, Abraham PR, van den Ende A, van Deventer SJH. Distribution and kinetics of lipoprotein-bound endotoxin. Infect Immun. 2001:69(5):2821-8.

22. Levine DM, Parker TS, Donnelly TM, Walsh A, Rubin AL. In vivo protection against endotoxin by plasma high density lipoprotein. Proc Natl Acad Sci U S A. 1993;90(24):12040-4

23. Kirschning CJ, Au-Young J, Lamping N, Reuter D, Pfeil D, Seilhamer JJ, et al. Similar organization of the lipopolysaccharide-binding protein (LBP) and phospholipid transfer protein (PLTP) genes suggests a common gene family of lipid-binding proteins. Genomics. 1997;46(3):416-25.

24. Vesy CJ, Kitchens RL, Wolfbauer G, Albers JJ, Munford RS Lipopolysaccharide-binding protein and phospholipid transfer protein release lipopolysaccharides from gram-negative bacterial membranes. Infect Immun. 2000;68(5):2410-7.

25. Brandenburg K, Jürgens G, Andrä J, Lindner B, Koch MHJ, Blume A, et al. Biophysical characterization of the interaction of high-density lipoprotein (HDL) with endotoxins. Eur J Biochem. 2002;269(23):5972-81.

26. Levels JHM, Abraham PR, van Barreveld EP, Meijers JCM, van Deventer SJH. Distribution and kinetics of lipoprotein-bound lipoteichoic acid. Infect Immun. 2003;71(6):3280-4.

27. Grunfeld C, Marshall M, Shigenaga JK, Moser AH, Tobias P, Feingold KR. Lipoproteins inhibit macrophage activation by lipoteichoic acid. J Lipid Res. 1999;40(2):245-52 
28. Cockerill GW, Rye KA, Gamble JR, Vadas MA, Barter PJ. High-density lipoproteins inhibit cytokine-induced expression of endothelial cell adhesion molecules. Arterioscler Thromb Vasc Biol. 1995;15(11):1987-94.

29. Cockerill GW, Huehns TY, Weerasinghe A, Stocker C, Lerch PG, Miller NE, et al. Elevation of plasma high-density lipoprotein concentration reduces interleukin-1-induced expression of E-selectin in an in vivo model of acute inflammation. Circulation. 2001;103(1):108-12.

30. McDonald MC, Dhadly P, Cockerill GW, Cuzzocrea S, Mota-Filipe H, Hinds CJ Miller NE, Thiemermann C. Reconstituted high-density lipoprotein attenuates organ injury and adhesion molecule expression in a rodent model of endotoxic shock. Shock. 2003;20(6):551-7.

31. Park S-H, Park JHY, Kang J-S, Kang Y-H. Involvement of transcription factors in plasma HDL protection against TNF-alpha-induced vascular cell adhesion molecule-1 expression. Int J Biochem Cell Biol. 2003;35(2):168-82.

32. Murphy AJ, Woollard KJ, Hoang A, Mukhamedova N, Stirzaker RA, McCormick SPA, et al. High-density lipoprotein reduces the human monocyte inflammatory response. Arterioscler Thromb Vasc Biol. 2008; 28(11):2071-7.

33. Westerterp M, Gourion-Arsiquaud S, Murphy AJ, Shih A, Cremers S, Levine $\mathrm{RL}$, et al. Regulation of hematopoietic stem and progenitor cell mobilization by cholesterol efflux pathways. Cell Stem Cell. 2012;11(2):195-206.

34. De Nardo D, Labzin LI, Kono H, Seki R, Schmidt SV, Beyer M, et al. Highdensity lipoprotein mediates anti-inflammatory reprogramming of macrophages via the transcriptional regulator ATF3. Nat Immunol. 2014; 15(2):152-60.

35. Zhu S, Wang Y, Chen W, Li W, Wang A, Wong S, et al. High-density lipoprotein (HDL) counter-regulates serum amyloid A (SAA)-induced sPLA2IIE and sPLA2-V expression in macrophages. PLoS One. 2016;11(11): e0167468.

36. Suzuki M, Pritchard DK, Becker L, Hoofnagle AN, Tanimura N, Bammler TK, et al. High-density lipoprotein suppresses the type I interferon response, a family of potent antiviral immunoregulators, in macrophages challenged with lipopolysaccharide. Circulation. 2010;122(19):1919-27.

37. Liadaki KN, Liu T, Xu S, Ishida BY, Duchateaux PN, Krieger JP, et al. Binding of high density lipoprotein (HDL) and discoidal reconstituted $\mathrm{HDL}$ to the $\mathrm{HDL}$ receptor scavenger receptor class B type I. Effect of lipid association and APOA-I mutations on receptor binding. J Biol Chem. 2000;275(28): 21262-71.

38. Kontush A, Therond P, Zerrad A, Couturier M, Négre-Salvayre A, de Souza $J A$, et al. Preferential sphingosine-1-phosphate enrichment and sphingomyelin depletion are key features of small dense HDL3 particles: relevance to antiapoptotic and antioxidative activities. Arterioscler Thromb Vasc Biol. 2007;27(8):1843-9.

39. Sattler K, Gräler M, Keul P, Weske S, Reimann C-M, Jindrová H, et al. Defects of high-density lipoproteins in coronary artery disease caused by low sphingosine-1-phosphate content: correction by sphingosine-1-phosphateloading. J Am Coll Cardiol. 2015;66(13):1470-85.

40. Badimon JJ, Santos-Gallego CG. HDL dysfunction: is the answer in the Sphinx's riddle? J Am Coll Cardiol. 2015;66(13):1486-8.

41. van der Stoep M, Korporaal SJA, Van Eck M. High-density lipoprotein as a modulator of platelet and coagulation responses. Cardiovasc Res. 2014; 103(3):362-71.

42. Viswambharan $H$, Ming $X-F$, Zhu $S$, Hubsch $A$, Lerch $P$, Vergères $G$, et al. Reconstituted high-density lipoprotein inhibits thrombin-induced endothelial tissue factor expression through inhibition of RhoA and stimulation of phosphatidylinositol 3-kinase but not Akt/endothelial nitric oxide synthase. Circ Res. 2004:94(7):918-25.

43. Li D, Weng S, Yang B, Zander DS, Saldeen T, Nichols WW, et al. Inhibition of arterial thrombus formation by ApoA1 Milano. Arterioscler Thromb Vasc Biol. 1999;19(2):378-83.

44. Griffin JH, Kojima K, Banka CL, Curtiss LK, Fernández JA. High-density lipoprotein enhancement of anticoagulant activities of plasma protein $\mathrm{S}$ and activated protein C. J Clin Invest. 1999;103(2):219-27.

45. Calkin AC, Drew BG, Ono A, Duffy SJ, Gordon MV, Schoenwaelder SM, et al. Reconstituted high-density lipoprotein attenuates platelet function in individuals with type 2 diabetes mellitus by promoting cholesterol efflux. Circulation. 2009;120(21):2095-104.

46. Watson AD, Berliner JA, Hama SY, La Du BN, Faull KF, Fogelman AM, et al. Protective effect of high density lipoprotein associated paraoxonase. Inhibition of the biological activity of minimally oxidized low density lipoprotein. J Clin Invest. 1995;96(6):2882-91.
47. Yan J-J, Jung J-S, Lee J-E, Lee J, Huh S-O, Kim H-S, et al. Therapeutic effects of lysophosphatidylcholine in experimental sepsis. Nat Med. 2004;10(2):1617.

48. Shih DM, Gu L, Xia YR, Navab M, Li WF, Hama S, et al. Mice lacking serum paraoxonase are susceptible to organophosphate toxicity and atherosclerosis. Nature. 1998;394(6690):284-7.

49. Kopprasch S, Pietzsch J, Graessler J. The protective effects of HDL and its constituents against neutrophil respiratory burst activation by hypochloriteoxidized LDL. Mol Cell Biochem. 2004;258(1-2):121-7.

50. Galley HF. Oxidative stress and mitochondrial dysfunction in sepsis. Br J Anaesth. 2011;107(1):57-64.

51. Suc I, Escargueil-Blanc I, Troly M, Salvayre R, Nègre-Salvayre A. HDL and ApoA prevent cell death of endothelial cells induced by oxidized LDL. Arterioscler Thromb Vasc Biol. 1997;17(10):2158-66.

52. Nofer JR, Levkau B, Wolinska I, Junker R, Fobker M, von Eckardstein A, et al. Suppression of endothelial cell apoptosis by high density lipoproteins (HDL) and HDL-associated lysosphingolipids. J Biol Chem. 2001;276(37):34480-5.

53. Theilmeier G, Schmidt C, Herrmann J, Keul P, Schäfers M, Herrgott I, et al. High-density lipoproteins and their constituent, sphingosine-1-phosphate, directly protect the heart against ischemia/reperfusion injury in vivo via the S1P3 lysophospholipid receptor. Circulation. 2006;114(13):1403-9.

54. Vilahur G, Gutiérrez M, Casaní L, Cubedo J, Capdevila A, Pons-Llado G, et al. Hypercholesterolemia abolishes high-density lipoprotein-related cardioprotective effects in the setting of myocardial infarction. J Am Coll Cardiol. 2015;66(21):2469-70

55. Santos-Gallego CG, Vahl TP, Goliasch G, Picatoste B, Arias T, Ishikawa K, et al. Sphingosine-1-phosphate receptor agonist fingolimod increases myocardial salvage and decreases adverse postinfarction left ventricular remodeling in a porcine model of ischemia/reperfusion. Circulation. 2016;133(10):954-66.

56. Santos-Gallego CG, Rosenson RS. Role of HDL in those with diabetes. Curr Cardiol Rep. 2014;16(9):512

57. Brunham LR, Kruit JK, Pape TD, Timmins JM, Reuwer AQ, Vasanji Z, et al. Beta-cell ABCA1 influences insulin secretion, glucose homeostasis and response to thiazolidinedione treatment. Nat Med. 2007;13(3):340-7.

58. Vergeer M, Brunham LR, Koetsveld J, Kruit JK, Verchere CB, Kastelein JJP, et al. Carriers of loss-of-function mutations in ABCA1 display pancreatic beta-cell dysfunction. Diabetes Care. 2010;33(4):869-74.

59. Tang S, Tabet F, Cochran BJ, Cuesta Torres LF, Wu BJ, Barter PJ, et al. Apolipoprotein A-I enhances insulin-dependent and insulin-independent glucose uptake by skeletal muscle. Sci Rep. 2019;9(1):1350.

60. Han R, Lai R, Ding Q, Wang Z, Luo X, Zhang Y, et al. Apolipoprotein A-I stimulates AMP-activated protein kinase and improves glucose metabolism. Diabetologia. 2007:50(9):1960-8.

61. Zhang Q, Zhang Y, Feng H, Guo R, Jin L, Wan R, et al. High density lipoprotein (HDL) promotes glucose uptake in adipocytes and glycogen synthesis in muscle cells. PLoS One. 2011;6(8):e23556.

62. Srivastava RAK. Dysfunctional HDL in diabetes mellitus and its role in the pathogenesis of cardiovascular disease. Mol Cell Biochem. 2018:440(1-2):167-87.

63. Drew BG, Duffy SJ, Formosa MF, Natoli AK, Henstridge DC, Penfold SA, et al. High-density lipoprotein modulates glucose metabolism in patients with type 2 diabetes mellitus. Circulation. 2009;119(15):2103-11.

64. Gordon BR, Parker TS, Levine DM, Saal SD, Wang JC, Sloan BJ, Barie PS, Rubin AL. Relationship of hypolipidemia to cytokine concentrations and outcomes in critically ill surgical patients. Crit Care Med. 2001;29(8):1563-8.

65. van Leeuwen HJ, Heezius EC, Dallinga GM, van Strijp JA, Verhoef J, van Kessel KP. Lipoprotein metabolism in patients with severe sepsis. Crit Care Med. 2003:31(5):1359-66.

66. Barlage S, Gnewuch C, Liebisch G, Wolf Z, Audebert FX, Gluck T, Frohlich D, Kramer BK, Rothe G, Schmitz G. Changes in HDL-associated apolipoproteins relate to mortality in human sepsis and correlate to monocyte and platelet activation. Intensive Care Med. 2009;35(11):1877-85.

67. Chien JY, Jerng JS, Yu CJ, Yang PC. Low serum level of high-density lipoprotein cholesterol is a poor prognostic factor for severe sepsis. Crit Care Med. 2005;33(8):1688-93.

68. Cirstea M, Walley KR, Russell JA, Brunham LR, Genga KR, Boyd JH. Decreased high-density lipoprotein cholesterol level is an early prognostic marker for organ dysfunction and death in patients with suspected sepsis. J Crit Care. 2017:38:289-94.

69. Tanaka S, Labreuche J, Drumez E, Harrois A, Hamada S, Vigué B, et al. Low $\mathrm{HDL}$ levels in sepsis versus trauma patients in intensive care unit. Ann Intensive Care. 2017;7(1):60 
70. Birjmohun RS, van Leuven SI, Levels JHM, van 't Veer C, Kuivenhoven JA, Meijers JCM, et al. High-density lipoprotein attenuates inflammation and coagulation response on endotoxin challenge in humans. Arterioscler Thromb Vasc Biol 2007;27(5):1153-1158.

71. Pirillo A, Catapano AL, Norata GD. HDL in infectious diseases and sepsis. Handb Exp Pharmacol. 2015;224:483-508.

72. de la Llera Moya M, McGillicuddy FC, Hinkle CC, Byrne M, Joshi MR, Nguyen $\checkmark$, et al. Inflammation modulates human $\mathrm{HDL}$ composition and function in vivo. Atherosclerosis. 2012;222(2):390-394.

73. Choudhury RP, Leyva F. C-Reactive protein, serum amyloid A protein, and coronary events. Circulation. 1999;100(15):e65-6.

74. Trinder M, Genga KR, Kong HJ, Blauw LL, Lo C, Li X, et al. Cholesteryl ester transfer protein influences high-density lipoprotein levels and survival in sepsis. Am J Respir Crit Care Med. 2019;199(7):854-62.

75. Lee SH, Park MS, Park BH, Jung WJ, Lee IS, Kim SY, Kim EY, Jung JY, Kang YA, Kim YS, et al. Prognostic implications of serum lipid metabolism over time during sepsis. Biomed Res Int. 2015;2015:789298.

76. Roveran Genga K, Lo C, Cirstea M, Zhou G, Walley KR, Russell JA, et al. Twoyear follow-up of patients with septic shock presenting with low HDL: the effect upon acute kidney injury, death and estimated glomerular filtration rate. J Intern Med. 2017;281(5):518-29.

77. Hacquebard M, Ducart A, Schmartz D, Malaisse WJ, Carpentier YA. Changes in plasma $\mathrm{LDL}$ and $\mathrm{HDL}$ composition in patients undergoing cardiac surgery. Lipids. 2007;42(12):1143-53.

78. Novak F, Vavrova L, Kodydkova J, Novak F, Hynkova M, Zak A, et al. Decreased paraoxonase activity in critically ill patients with sepsis. Clin Exp Med. 2010;10(1):21-5.

79. Kotosai M, Shimada S, Kanda M, Matsuda N, Sekido K, Shimizu Y, et al. Plasma HDL reduces nonesterified fatty acid hydroperoxides originating from oxidized LDL: a mechanism for its antioxidant ability. Lipids. 2013;48(6): 569-78.

80. Van Lenten BJ, Hama SY, de Beer FC, Stafforini DM, Mclntyre TM, Prescott $\mathrm{SM}$, et al. Anti-inflammatory HDL becomes pro-inflammatory during the acute phase response. Loss of protective effect of HDL against LDL oxidation in aortic wall cell cocultures. J Clin Invest. 1995;96(6):2758-67.

81. Vaisar T, Tang C, Babenko I, Hutchins P, Wimberger J, Suffredini AF, et al. Inflammatory remodeling of the HDL proteome impairs cholesterol efflux capacity. J Lipid Res. 2015;56(8):1519-30.

82. Sharma NK, Tashima AK, Brunialti MKC, Ferreira ER, Torquato RJS, Mortara RA, et al. Proteomic study revealed cellular assembly and lipid metabolism dysregulation in sepsis secondary to community-acquired pneumonia. Sci Rep. 2017;7(1):15606.

83. Sharma NK, Ferreira BL, Tashima AK, Brunialti MKC, Torquato RJS, Bafi A, et al. Lipid metabolism impairment in patients with sepsis secondary to hospital acquired pneumonia, a proteomic analysis. Clin Proteomics. 2019; 16:29.

84. Guirgis FW, Leeuwenburgh C, Grijalva V, Bowman J, Kalynych C, Moldawer $L$, et al. HDL cholesterol efflux is impaired in older patients with early sepsis: a subanalysis of a prospective pilot study. Shock Augusta Ga. 2017;18.

85. Ortiz-Munoz G, Couret D, Lapergue B, Bruckert E, Meseguer E, Amarenco P, et al. Dysfunctional HDL in acute stroke. Atherosclerosis. 2016;253:75-80.

86. Tanaka S, Diallo D, Delbosc S, Genève C, Zappella N, Yong-Sang J, et al. High-density lipoprotein (HDL) particle size and concentration changes in septic shock patients. Ann Intensive Care. 2019;9(1):68.

87. El Harchaoui K, Arsenault BJ, Franssen R, Després J-P, Hovingh GK, Stroes ESG, et al. High-density lipoprotein particle size and concentration and coronary risk. Ann Intern Med. 2009;150(2):84-93.

88. Mutharasan RK, Thaxton CS, Berry J, Daviglus ML, Yuan C, Sun J, et al. HDL efflux capacity, HDL particle size, and high-risk carotid atherosclerosis in a cohort of asymptomatic older adults: the Chicago Healthy Aging Study. J Lipid Res. 2017;58(3):600-6.

89. Morin EE, Guo L, Schwendeman A, Li X-A. HDL in sepsis - risk factor and therapeutic approach. Front Pharmacol. 2015;6:244.

90. Moreira RS, Irigoyen M, Sanches TR, Volpini RA, Camara NOS, Malheiros DM, et al. Apolipoprotein A-I mimetic peptide 4F attenuates kidney injury, heart injury, and endothelial dysfunction in sepsis. Am J Physiol Regul Integr Comp Physiol. 2014;307(5):R514-24.

91. Zhang X, Wang L, Chen B. Recombinant HDL (Milano) protects endotoxinchallenged rats from multiple organ injury and dysfunction. Biol Chem. 2015;396(1):53-60.
92. Kwon WY, Suh GJ, Kim KS, Kwak YH, Kim K. 4F, apolipoprotein Al mimetic peptide, attenuates acute lung injury and improves survival in endotoxemic rats. J Trauma Acute Care Surg. 2012;72(6):1576-83.

93. Casas AT, Hubsch AP, Doran JE. Effects of reconstituted high-density lipoprotein in persistent gram-negative bacteremia. Am Surg. 1996;62(5): 350-5.

94. Guo L, Ai J, Zheng Z, Howatt DA, Daugherty A, Huang B, et al. High density lipoprotein protects against polymicrobe-induced sepsis in mice. J Biol Chem. 2013;288(25):17947-53.

95. Navab M, Anantharamaiah GM, Reddy ST, Hama S, Hough G, Grijalva VR, et al. Apolipoprotein A-I mimetic peptides. Arterioscler Thromb Vasc Biol. 2005;25(7):1325-31.

96. Zhang Z, Datta G, Zhang Y, Miller AP, Mochon P, Chen Y-F, et al. Apolipoprotein A-I mimetic peptide treatment inhibits inflammatory responses and improves survival in septic rats. Am J Physiol Heart Circ Physiol. 2009;297(2):H866-73.

97. Datta G, Gupta H, Zhang Z, Mayakonda P, Anantharamaiah GM, White CR. HDL mimetic peptide administration improves left ventricular filling and cardiac output in lipopolysaccharide-treated rats. J Clin Exp Cardiol 2011 22; 2(172).

98. Lerch PG, Förtsch V, Hodler G, Bolli R. Production and characterization of a reconstituted high density lipoprotein for therapeutic applications. Vox Sang. 1996;71(3):155-64.

99. Tanaka S, Genève C, Zappella N, Yong-Sang J, Planesse C, Louedec L, et al. Reconstituted high-density lipoprotein therapy improves survival in mouse models of sepsiS. Anesthesiology. 2020;132(4):825-38.

100. Patel S, Drew BG, Nakhla S, Duffy SJ, Murphy AJ, Barter PJ, et al. Reconstituted high-density lipoprotein increases plasma high-density lipoprotein anti-inflammatory properties and cholesterol efflux capacity in patients with type 2 diabetes. J Am Coll Cardiol. 2009;53(11):962-71.

101. Tardif J-C, Grégoire J, L'Allier PL, Ibrahim R, Lespérance J, Heinonen TM, et al. Effects of reconstituted high-density lipoprotein infusions on coronary atherosclerosis: a randomized controlled trial. JAMA. 2007;297(15):1675-82.

102. Gordon BR, Parker TS, Levine DM, Feuerbach F, Saal SD, Sloan B-J, et al. Neutralization of endotoxin by a phospholipid emulsion in healthy volunteers. J Infect Dis. 2005;191(9):1515-22.

103. Dellinger RP, Tomayko JF, Angus DC, Opal S, Cupo MA, McDermott S, et al. Efficacy and safety of a phospholipid emulsion (GR270773) in Gramnegative severe sepsis: results of a phase II multicenter, randomized, placebo-controlled, dose-finding clinical trial. Crit Care Med. 2009;37(11): 2929-38.

104. Pajkrt D, Doran JE, Koster F, Lerch PG, Arnet B, van der Poll T, et al. Antiinflammatory effects of reconstituted high-density lipoprotein during human endotoxemia. J Exp Med. 1996;184(5):1601-8.

105. Pajkrt D, Lerch PG, van der Poll T, Levi M, Illi M, Doran JE, et al. Differential effects of reconstituted high-density lipoprotein on coagulation, fibrinolysis and platelet activation during human endotoxemia. Thromb Haemost. 1997; 77(2):303-7.

\section{Publisher's Note}

Springer Nature remains neutral with regard to jurisdictional claims in published maps and institutional affiliations. 